\section{Unique Organic Acid Profile of Rabbiteye vs. Highbush Blueberries}

\author{
Mark K. Ehlenfeldt ${ }^{1}$ \\ Rutgers Blueberry and Cranberry Research Center, Penn State Forest Road, \\ Chatsworth, NJ 08019
}

Filmore I. Meredith ${ }^{2}$

Richard B. Russell Agricultural Research Center, College Station Road, Athens, GA 30613

\author{
James R. Ballington ${ }^{3}$ \\ Department of Horticultural Science, North Carolina State University, Raleigh, \\ NC 27695-7609
}

Additional index words. Vaccinium corymbosum, Vaccinium ashei, citric, malic, succinic, quinic, albino

\begin{abstract}
The fruit of six highbush (Vaccinium corymbosum L.) cultivars and eight rabbiteye ( $V$. ashei Reade) cultivars and selections were evaluated by high-performance liquid chromatography for levels of the commonly found organic acids, citric, malic, succinic, and quinic. The two cultivar groups possessed distinctive patterns of relative organic acid proportions that could unambiguously separate pure rabbiteye and highbush clones in a principal component analysis. Highbush clones were characterized by high citric acid content, with percentages averaging $75 \%$ (range $38 \%$ to $90 \%$ ). Succinic acid was the second most plentiful acid, averaging $17 \%$. In contrast, rabbiteye cultivars and selections contained $10 \%$ citric acid, and no clone had $>22 \%$. Succinic acid and malic acid were found in greater quantities than in highbush, averaging $50 \%$ and $34 \%$, respectively. Analysis of the fruit of seven albino-fruited highbush selections exhibited a profile similar to standard highbush cultivars, but with a citric acid average of $<50 \%$, and proportionally greater amounts of succinic and quinic acids. Given the differences in sensory quality of these four acids, it is likely that acid partitioning patterns can largely account for some of the perceived flavor differences between rabbiteye and highbush blueberries. Because several current breeding efforts involve hybridization between highbush and rabbiteye blueberries, a consideration of acid composition of breeding parents maybe worthwhile.
\end{abstract}

Evaluating biochemical traits can be useful for understanding taxonomic relationships among species, and for evaluating the variability found within and between plant populations. Biochemical screening also can reveal the potential of plant genotypes as sources of desirable genes or gene combinations for subsequent transfer within breeding programs. In recent years, several studies have used biochemical analyses of anthocyanins, aglycones, and aglycone-sugars in blueberry fruit to delineate differences among Vaccinium species (Baj et al., 1983; Ballington et al., 1987; Francis et al., 1966; Makus and Ballinger, 1973). However, comparatively little examination has been made of the organic acids in the fruit of Vaccinium species. The earliest reference regarding the organic acid composition of highbush blueberries is that of Nelson (1927) who reported that the "predominating acid of the

\footnotetext{
Received for publication 30 Aug. 1993. Accepted for publication 6 Nov. 1993. The cost of publishing this paper was defrayed in part by the payment of page charges. Under postal regulations, this paper therefore must be hereby marked advertisement solely to indicate this fact.

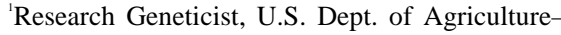
Agricultural Research Service.

${ }^{2}$ Resarch Chemist, U.S. Dept. of Agriculture-Agricultural Research Service.

${ }^{3}$ Professor.
}

blueberry is citric, with a little 1-malic acid." Markakis et al. (1963) identified 16 organic acids in highbush blueberry fruit ('Rubel' and 'Jersey') and found the predominant acids to be citric, malic, quinic, and chlorogenic (a phenolic acid) at percentages averaging $70 \%$,
Table 1. Clones analyzed for fruit organic acid content.
$7 \%, 4 \%$, and $16 \%$, respectively. Kushman and Ballinger (1968) found, on average, 95\% citric acid and $1 \%$ to $2 \%$ each of quinic acid and malic acid in ripe 'Wolcott' fruit. Although the total quantity of acid declines during ripening in highbush fruit, most changes are the result of a decrease in citric acid. Kushman and Ballinger (1968) found a 30\% to $40 \%$ decrease in the level of citric acid between ripe and overripe fruit, but no major changes in the other acids. Because citric acid so dominated the total composition, although the minor acids increased relatively, these changes amounted to at most a $2.4 \%$ increase relative to the original proportion. No reports of rabbiteye fruit composition were found.

In the course of fruit evaluation, we noted that clones containing $V$. ashei germplasm displayed titration curves whose shape differed from that of highbush clones. The shape of these curves with respect to their inflection points suggested that malic acid $\left(\mathrm{pK}_{\mathrm{a} 2}=5.1\right)$ and succinic acid $\left(\mathrm{pK}_{\mathrm{a} 2}=5.2\right)$ composed a major portion of the organic acids, as opposed to citric acid $\left(\mathrm{pK}_{\mathrm{a3}}=6.4\right)$, which is the predominant acid in highbush clones.

\section{Materials and Methods}

We examined the organic acid composition of rabbiteye cultivars and selections and highbush clones, including cultivars and albino-fruited selections. Highbush and rabbiteye clones selected for this study encompassed abroad range of ripening dates and acid levels and included both cultivars and wild selections (Table 1). The fruit of six highbush cultivars were collected at the Rutgers Blueberry and Cranberry Research Center, Chatsworth, N. J., from plants that had been stripped of ripe fruit 3 days before collection, to ensure that collected fruit were newly ripened. All other collections were of firm mature fruit, but no distinctions were made as to precise ripening time. Albino highbush fruit were collected at the same location as high-

\begin{tabular}{|c|c|}
\hline $\begin{array}{l}\text { Selection } \\
\text { or cultivar }\end{array}$ & Comments \\
\hline \multicolumn{2}{|l|}{ Highbush } \\
\hline Bluetta & Early season, low acid, 1/4 Vaccinium angustifolium \\
\hline Earliblue & Early season, low acid, $1 / 16 \mathrm{~V}$. angustifolium \\
\hline Bluecrop & Midseason, moderate acid, 1/16 V. angustifolium \\
\hline Elizabeth & Midseason, low acid \\
\hline Jersey & Mid-late season, moderate acid \\
\hline Elliott & Late season, high acid \\
\hline \multicolumn{2}{|l|}{ Rabbiteye } \\
\hline Climax & Early season, moderate acid \\
\hline Premier & Early midseason, low acid \\
\hline Tifblue & Midseason, high acid \\
\hline Centurion & Late season, moderate acid \\
\hline NC 2140 & Late, high acid, mild flavor, western Florida wild selection \\
\hline T 376 & Moderate acid, Georgia wild selection \\
\hline NC 84-9-1 & Moderate acid, North Carolina wild selection \\
\hline \multicolumn{2}{|c|}{ Albino-fruited highbush hybrids } \\
\hline $\mathrm{G} 434$ & Highbush with $1 / 16 \mathrm{~V}$. darrowi, $1 / 32 \mathrm{~V}$. tenellum, 1/32 V. ashei \\
\hline G 435 & Highbush with $1 / 16 \mathrm{~V}$. darrowi, 1/32 V. tenellum, 1/32 V. ashei \\
\hline G 604 & New Jersey highbush (G 144) x Florida highbush (Fla 4-76) \\
\hline ALB-12 & New Jersey highbush (G 226) x G 435 \\
\hline ALB-56 & New Jersey highbush (G 226) x G 435 \\
\hline ALB-84 & New Jersey highbush (G 226) x G 435 \\
\hline NJ 856-1 & Triploid, $4 \times \mathrm{G} 434 \times 2 \times V$. corymbosum albino \\
\hline
\end{tabular}


bush cultivar fruit. Rabbiteye fruit were collected from potted plants grown outdoors in New Jersey and from plants located at North Carolina State Univ. Agricultural Research Stations at Castle Hayne and Jackson Springs. Fruit were stored at $-40 \mathrm{C}$ until acid extraction.

Chemical analysis of the fruit consisted of taking $5 \mathrm{~g}$ of the frozen blueberries, cutting each berry into four sections, and dropping the sections into 75 to $80 \mathrm{ml}$ of boiling methanol. The cut sections were added at a rate such that the methanol did not stop boiling. After the last fruit section was added, the methanolfruit solution was heated for an additional 15 rein, cooled, then blended with a Polytron (model PT 10-35; Brinkman Instruments, Westbury, N.Y.) at 27,000 rpm for $30 \mathrm{sec}$. About $1 \mathrm{~g}$ of Hyflo Super Cel (Fisher Scientific, Pittsburgh) was added, and the sample was filtered under vacuum. To aid in extraction, the filtration residue was resuspended in $70 \%$ methanol : water and filtered a second time. After the two extracts were combined, the sample was brought to dryness on a rotary evaporator. The sample was brought to a volume of $10 \mathrm{ml}$ and passed through a $4 \times 1-\mathrm{cm}$ column of 200-400 mesh AG 1-X8 resin (Bio-Rad, Hercules, Calif.). The column was washed with three volumes of water, and the acids eluted with $30 \mathrm{ml}$ of $10 \mathrm{~N}$ formic acid. Formic acid was removed from the purified acid extract with a rotary evaporator. Five milliliters of methanol was added to the dried sample, and the sample was again brought to dryness. This was repeated until an acetic acid aroma could not be detected in the flask. The acid sample was quantitatively removed from the round-bottom flask and brought to $5 \mathrm{ml}$.

High-performance liquid chromatography separations were made isocratically on a $30 \times$ 0.78-cm Bio-Rad Aminex ion-exclusive HPX-87H organic acid column. A Waters guard column was packed with Bio-Rad AG 50 resin 100-200 mesh in the sulfonic form. Column eluting solvent was $0.09 \mathrm{~N} \mathrm{H}_{2} \mathrm{SO}_{4}$ at a flow rate of $0.5 \mathrm{ml} \cdot \mathrm{min}^{-1}$. Eluting peaks were detected by ultraviolet absorption at $210 \mathrm{~nm}$. Acid standards (Sigma Chemical Co., St. Louis) were chromatographed for quantitation and determination of retention time, and also were co-chromatographed with the sample for identification. Data were statistically analyzed for differences due to species or type (i.e., highbush, rabbiteye, albino hybrids) with respect to the individual organic acid components and total acidity using the general linear model (GLM) procedure of the Statistical Analysis System (SAS Institute Inc., 1989). Means were tested with a Student-NewmanKeuls multiple comparison procedure. Because preliminary analysis showed no differences between the rabbiteye materials collected in New Jersey and North Carolina, the data from these selections were pooled and analyzed as a single group. Principal component analysis was performed with MSTATC statistical analysis software (Michigan State Univ.).

\section{Results and Discussion}

Four organic acids, citric, malic, succinic, and quinic, comprised virtually all of the acid found in highbush and rabbiteye blueberries. Unlike several previous studies, we identified quantities of succinic acid in both highbush and rabbiteye cultivars. Previously, succinic acid had been noted only as a minor compo- nent by Markakis et al. (1963). The isolation and quantification procedures we used and co-chromatography with acid standards make us confident that this identification is correct. The isolation procedures used also eliminated phenolic acids, such as chlorogenic acid, which were found in other studies.

Citric acid was the predominant organic acid in the highbush cultivars, having an average value of $75 \%$ (Table 2 ). The next most common acid was succinic acid, which was present at an average level of $17 \%$. The remaining organic acid content was roughly split between malic and quinic acids. 'Bluetta', which is $1 / 4 \mathrm{~V}$. angustifolium L., had a low percentage of citric acid (38\%) and an overall profile that was considerably different from the essentially pure $V$. corymbosum cultivars. 'Earliblue' and 'Bluecrop', both of which are 1/16 V. angustifolium, appear to be indistinguishable from the pure highbush clones. If 'Bluetta' is not included in the comparison, the highbush cultivars present a very uniform profile and have an average of $83 \%$ citric, $2 \%$ malic, $11 \%$ - succinic, and $5 \%$ quinic acid. Across these cultivars, citric acid ranged from $74 \%$ ('Earliblue') to $90 \%$ ('Elliott').

In contrast, succinic and malic acids were the predominant acids in rabbiteye cultivars and selections, averaging $50 \%$ and $33 \%$, respectively. Although succinic acid dominated on the average, individual selections and cultivars were found in which malic acid was the dominant acid (e.g., 'Briteblue', T376). Among the rabbiteye clones, citric acid averaged $10 \%$, and was never found to be $>22 \%$. Quinic acid was consistently present only as a minor constituent, averaging $6 \%$.

Comparisons of the total acid concentra-

Table 2. Organic acid composition of highbush, rabbiteye, and albino-fruited highbush selections.

\begin{tabular}{|c|c|c|c|c|c|c|c|c|c|c|}
\hline \multirow{2}{*}{$\begin{array}{l}\text { Cultivar or } \\
\text { selection }\end{array}$} & \multicolumn{4}{|c|}{ Acid percentage $(f w)^{z, y}$} & \multicolumn{5}{|c|}{ Acid concn $(\mathrm{mg} / \mathrm{g} \text { fw })^{y}$} & \multirow{2}{*}{$\begin{array}{c}\text { Citric } \\
\text { acid } \\
\text { equivalent } \\
(\mathrm{mg} / \mathrm{g} \text { fw })^{y}\end{array}$} \\
\hline & Citric & Malic & Succinic & Quinic & Citric & Malic & Succinic & Quinic & Total & \\
\hline \multicolumn{11}{|l|}{ Highbush } \\
\hline Bluetta & 38 & 11 & 47 & 4 & 6.11 & 1.79 & 7.62 & 0.70 & 16.22 & 12.55 \\
\hline Earliblue & 74 & 2 & 22 & 2 & 10.73 & 0.32 & 3.12 & 0.29 & 14.46 & 13.10 \\
\hline Jersey & 78 & 1 & 11 & 9 & 5.98 & 0.10 & 0.85 & 0.71 & 7.64 & 6.84 \\
\hline Bluecrop & 85 & 2 & 8 & 5 & 8.59 & 0.17 & 0.83 & 0.46 & 10.05 & 9.40 \\
\hline Elizabeth & 86 & 2 & 8 & 5 & 8.28 & 0.15 & 0.73 & 0.47 & 9.63 & 9.02 \\
\hline Elliott & 90 & 2 & 6 & 2 & 16.54 & 0.38 & 1.06 & 0.45 & 18.43 & 17.64 \\
\hline Mean & $75.2 \mathrm{c}$ & $3.3 \mathrm{a}$ & $16.9 \mathrm{a}$ & $4.6 \mathrm{a}$ & 9.37 & 0.48 & 2.37 & 0.51 & 12.74 & $11.42 \mathrm{~b}$ \\
\hline \multicolumn{11}{|l|}{ Rabbiteye } \\
\hline Briteblue & 3 & 68 & 22 & 7 & 0.24 & 6.21 & 2.06 & 0.65 & 9.16 & 5.91 \\
\hline Tifblue & 4 & 31 & 61 & 3 & 0.63 & 5.20 & 10.15 & 0.57 & 16.55 & 10.95 \\
\hline NC 84-9-1 & 8 & 22 & 58 & 13 & 1.19 & 3.37 & 8.84 & 1.92 & 15.32 & 9.88 \\
\hline Climax & 9 & 26 & 63 & 2 & 1.51 & 4.47 & 10.86 & 0.34 & 17.18 & 11.74 \\
\hline Т 376 & 10 & 52 & 34 & 4 & 1.66 & 8.52 & 5.66 & 0.59 & 16.43 & 11.21 \\
\hline Centurion & 11 & 15 & 70 & 4 & 2.43 & 3.29 & 15.45 & 0.91 & 22.08 & 15.10 \\
\hline NC 2140 & 16 & 26 & 56 & 2 & 3.90 & 6.12 & 13.23 & 0.47 & 23.72 & 16.83 \\
\hline Premier & 22 & 29 & 38 & 11 & 2.34 & 3.00 & 3.98 & 1.12 & 10.44 & 7.32 \\
\hline Mean & $10.4 \mathrm{a}$ & $33.6 \mathrm{~b}$ & $50.4 \mathrm{~b}$ & $5.7 \mathrm{a}$ & 1.74 & 5.02 & 8.78 & 0.82 & 16.36 & $11.12 \mathrm{~b}$ \\
\hline \multicolumn{11}{|c|}{ Albino-fruited highbush hybrids } \\
\hline G 434 & 22 & 6 & 10 & 61 & 0.93 & 0.27 & 0.43 & 2.60 & 4.23 & 2.25 \\
\hline ALB-84 & 51 & 9 & 18 & 22 & 4.78 & 0.89 & 1.67 & 2.05 & 9.39 & 7.15 \\
\hline AL $8-12$ & 52 & 9 & 23 & 16 & 3.15 & 0.53 & 1.38 & 0.96 & 6.02 & 4.73 \\
\hline G 435 & 53 & 18 & 20 & 9 & 2.40 & 0.81 & 0.91 & 0.42 & 4.54 & 3.67 \\
\hline G 604 & 56 & 5 & 29 & 9 & 2.21 & 0.21 & 1.14 & 0.36 & 3.92 & 3.22 \\
\hline ALB-56 & 57 & 10 & 12 & 20 & 4.06 & 0.72 & 0.86 & 1.43 & 7.07 & 5.57 \\
\hline NJ 856-1 & 57 & 10 & 12 & 20 & 4.33 & 0.76 & 0.92 & 1.53 & 7.54 & 5.94 \\
\hline Mean & $49.9 \mathrm{~b}$ & $9.7 \mathrm{a}$ & $17.8 \mathrm{a}$ & $22.6 \mathrm{~b}$ & 3.12 & 0.60 & 1.04 & 1.34 & 6.10 & $4.65 \mathrm{a}$ \\
\hline
\end{tabular}


tion in highbush and rabbiteye clones revealed that on the basis of milligrams of acid per gram of fresh weight, the rabbiteye clones possessed higher levels of acid (16.4-mg/g fresh weight) than did highbush clones $(12.7 \mathrm{mg} / \mathrm{g}$ fresh weight). This comparison is deceptive, however, because citric acid possesses three dissociable hydrogen atoms compared to two each for malic and succinic and one for quinic acid. When acid content is expressed as citric acid equivalents based on titratable hydrogens, the acid contents of the two groups are not significantly different (Table 2). However, other studies that looked at broader ranges of genotypes have generally found rabbiteye clones to have lower titratable acidity than highbush clones (Ballington et al., 1984; Makus and Morris, 1987).

The albino-fruited highbush clones that were examined have germplasm introgressed from $V$. darrowi Camp, $V$. ashei, and $V$. tenellum Aiton, and hence do not represent pure highbush and do not allow conclusions to be drawn as to whether any differences seen are due strictly to albinism. Nonetheless, an examination of these clones is interesting in light of the low anthocyanin levels (Ballinger et al., 1972) and pinkish pigmentation, the bland flavor, and the unpleasant aftertaste often found in albino fruit. Overall, the albinos exhibited profiles similar to those of highbush clones, but with lower levels of citric acid, averaging 50\%. Quantities of quinic acid were proportionally higher at $23 \%$, and malic acid was slightly higher than in typical highbush levels at $10 \%$. Succinic acid remained relatively unchanged. Total acid content of the albinos, which averaged $4.7 \mathrm{mg} / \mathrm{g}$ fresh weight in citric acid equivalents, was significantly less than that of either highbush or rabbiteye clones. The combined features of higher quinic acid and low concentrations of total acid appear to be a distinguishing feature of albino fruit.

Statistical analysis using highbush, rabbiteye, and highbush albino groupings revealed highly significant differences for citric, malic, and succinic acids $(P \leq 0.001)$. Quinic acid exhibited significant differences $(\mathrm{F}=$ 5.94, $P \leq 0.010)$. Student-Newman-Keuls multiple mean comparisons showed significant differences in the mean values for citric, malic, and succinic acid between highbush and rabbiteye clones (Table 2). Albino-fruited highbush means were different from highbush for citric acid, but not for malic and succinic acid. For quinic acid, highbush and rabbiteye clones grouped together. Albino-fruited highbush, having high levels of quinic acid, appeared as a separate group.

A principal component analysis was used to examine the relative groupings of these materials (Fig. 1). This analysis, using relative percentages of citric, succinic, and quinic acid, partitioned $96 \%$ of the variation in organic acid composition into two vectors, PRIN 1 and PRIN 2. PRIN 1 had positive loadings for citric acid and quinic acid (0.646 and 0.260, respectively) and a negative loading for succinic acid $(-0.717)$ and accounted for $61 \%$ of the total variation. PRIN 2 had a positive

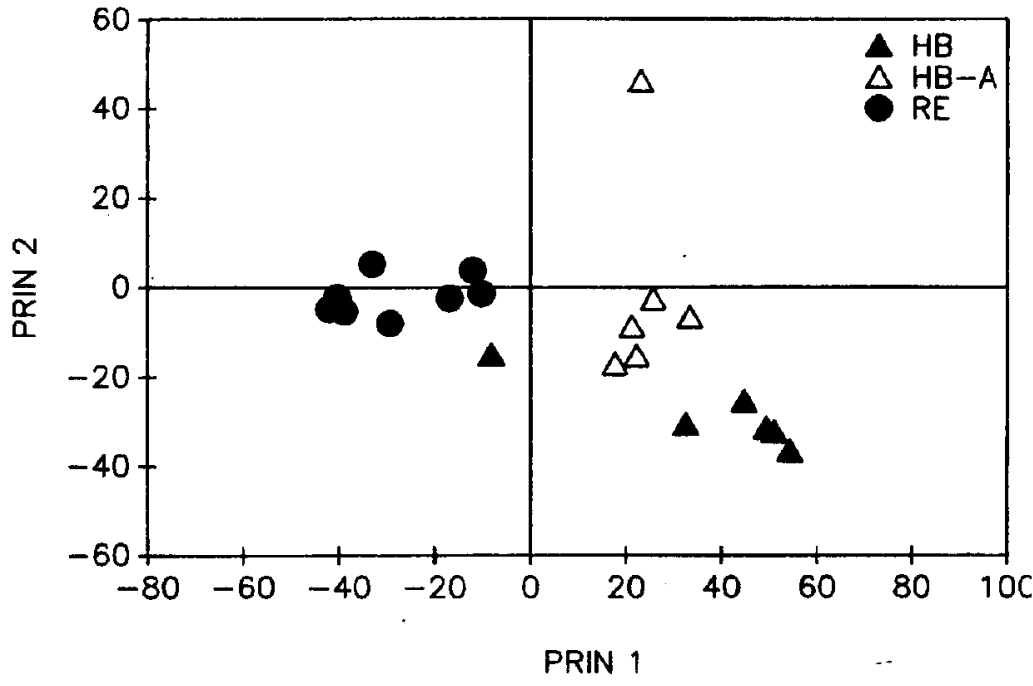

Fig. 1. Principal component graph of highbush (HB), albino highbush (HB-A), and rabbiteye (RE) selections.

loading for quinic acid (0.904) and negative loadings for citric and succinic acid $(-0.423$ and -0.054 , respectively), and accounted for $35 \%$ of the total variation. Pure highbush cultivars exhibited a distinct and tight clustering, but the introgressed cultivar, 'Bluetta', was an outlier, graphing close to the rabbiteye clones. Rabbiteye clones, both cultivars and selections, also exhibited a tight and distinct clustering, well separated from all of the highbush clones except 'Bluetta'. This tight clustering of rabbiteye clones was particularly notable because these clones represented not only cultivated and wild selections, but also collections from North Carolina and New Jersey. Albino-fruited clones were clustered intermediate to the two groups but relatively closer to the highbush clones. G 434, a clone with a high percentage of quinic acid, appeared as an outlier.

This study represents an initial characterization of organic acids in fruit of rabbiteye blueberry and broadens the scope of previous examinations of highbush material. The differences observed between these two cultivar groups offer indications that $V$. corymbosum and $V$. ashei are distinct entities that should not be grouped together taxonomically into $V$. corymbosum as has been done recently by Vander Kloet (1988). Because information has previously been unavailable on the organic acids of rabbiteye blueberries, little is known regarding the correlation of organic acids with perceptible flavor differences. If acid composition affects flavor, as might be expected from descriptions of pure acid solutions (Budavari, 1989), inheritance of these patterns may bean important consideration in ongoing breeding programs that are pursuing hybridization between these two groups. Our personal observations (Ehlenfeldt, Ballington) have been that fruit of the rabbiteye cultivar Premier, which was found to have $22 \%$ citric acid, have a brighter taste than most rabbiteye cultivars, and is generally similar to the flavor of highbush fruit. Acid profile differences may also have a bearing on other important factors such as fruit color development, decay susceptibility, and insect and bird predation.

\section{Literature Cited}

Baj, A., E. Bomardelli, B. Gabetta, and E.M. Martinelli, 1983. Qualitative and quantitative evacuation of Vaccinium myrtillus anthocyanins by high resolution gas chromatography and high performance liquid chromatography. J. Chromatography 279:365-372.

Ballinger, W.E., E.P. Maness, G.J. Galletta, and L.J. Kushman, 1972. Anthocyanins of ripe fruit of a "pink-fruited" hybrid of highbush blueberries, Vaccinium corymbosum L.J. Amer. Soc. Hort. Sci. 97:381-384.

Ballington, J.R., W.E. Ballinger, and E.P. Maness. 1987. Interspecific differences in the percentage of anthocyanins, aglycones and aglycone-sugars in the fruit of seven species of blueberries. J. Amer. Soc. Hort. Sci. 112:859-864.

Ballington, J.R., W.E. Ballinger, W.H. Swallow, G.J. Galletta, and L.J. Kushman. 1984. Fruit quality characterization of 11 Vaccinium species. J. Amer. Soc. Hort Sci. 109:684-689.

Budavari, S. (ed.). 1989. Merck index. 11th ed. 1989. Merck \& Co., Rahway, N.J.

Francis, F.J., J.B. Harborne, and W.G. Barker. 1966. Anthocyanins in the lowbush blueberry, Vaccinium angustifolium. J. Food Sci. 31:583587.

Kushman, L.J. and W.E. Ballinger. 1968. Acid and sugar changes during ripening in Wolcott blueberries. Proc. Amer. Soc. Hort. Sci. 92:290295.

Makus, D.J. and W.E. Batlinger. 1973. Characterization of anthocyanins during ripening of fruit of Vaccinium corymbosum L. cv. Wolcott. J. Amer. Soc. Hort. Sci. 98:99-101.

Makus, D.J. and J.R. Morris. 1987. Highbush vs. rabbiteye blueberry: A comparison of fruit quality. Arkansas Farm Res., May-June 1987.

Markakis, P., A. Jarczyk, and S.P. Krishna. 1963. Nonvolatile acids of blueberries. Agr. \& Food Chem. 11:8-11,

Nelson, E.K. 1927. The non-volatile acids of the pears, quince, apple, loganberry, blueberry, cranberry, lemon and pomegranate. J. Amer. Chem. Soc. 49:1300-1302.

Vander Kloet, S.P. 1988. The genus Vaccinium in North America. Agr. Canada, Ottawa, Publ. 1828. 